\title{
A literatura na interpretação do Brasil e de Portugal segundo Antonio Candido E EdUARDo LOURENÇO
}

\author{
Brazil's and Portugal's interpretation about \\ literature according to Antonio Candido and Eduardo \\ Lourenço
}

Patrícia da Silva Cardoso*

RESUMO

Portugal e Brasil têm em comum uma língua e um passado. Apesar desse vínculo, quando se estuda a literatura dos dois países, seja no Brasil, seja em Portugal, a tendência é a de se separarem as produções, como se de duas séries literárias distintas se tratasse. Sem nos aprofundarmos nos motivos para tal, vale lembrar o papel de um texto como "Literatura e cultura de 1900 a 1945", de Antonio Candido, na constituição de um distanciamento entre os dois países, marcado pelo esforço brasileiro de independência da matriz portuguesa, que se teria consolidado plenamente na altura do movimento modernista. $\mathrm{O}$ artigo de Candido atribui um papel central à literatura, que transcende os limites do campo estético para ser instrumento da

* UFPR 
construção da autoimagem nacional. Apesar do distanciamento no que diz respeito à crítica literária praticada nos dois países, é possível observar, em um artigo como "Da literatura como interpretação de Portugal”, de Eduardo Lourenço, um esforço análogo ao de Candido quando coloca a literatura naquela posição privilegiada. A este artigo interessará discutir os pontos de contato e de afastamento dos dois críticos em suas abordagens do literário como instância de reflexão privilegiada acerca da cultura e das identidades nacionais brasileira e portuguesa.

Palavras-chave: Eduardo Lourenço; Antonio Candido; crítica literária.

\begin{abstract}
Portugal and Brazil have a language and a history in common. Despite this bond, whenever critics study the Literature of either Brazil or Portugal, they tend to set them apart, as if part of two distinct literary traditions. Without discussing the reasons for such an attitude, it is worth recalling the contribution of Antonio Candido's "Literatura e cultura de 1900 a 1945 [Literature and culture, from 1900 to 1945]", in terms of establishing a distance between those two countries, stressed by the Brazilian effort to get independent from the Portuguese sources, completed by the time of the Modernist Movement. Candido's article assigns a central role to Literature, one that transcends the borders of the aesthetic field to be an instrument in the building of national self-image. In spite of the distance between the critical approaches in these two countries, it is possible to note, in an article such as Eduardo Lourenço's "Da literatura como interpretação de Portugal" [Literature as a means of interpreting Portugal], an effort corresponding to that of Candido's, while placing Literature in such a privileged position. This paper's interest is to discuss the similarities and differences between these two critical approaches concerning Literature as a privileged means of discussing culture and Identity in both Brazil and Portugal.
\end{abstract}

Keywords: Eduardo Lourenço; Antonio Candido; Literary criticism. 
Portugal e Brasil têm em comum uma língua e um passado, dois elementos importantes para a manutenção de uma proximidade cultural, que no entanto não tem sido a marca da relação entre os dois países, norteada, contemporaneamente, por uma assimetria de interesses: no plano da cultura de massa, os portugueses parecem muito mais atentos ao que ocorre no Brasil, das novelas à música, passando pelo sucesso de alguns títulos literários de qualidade duvidosa, o mesmo não se passando com o público brasileiro, meio em que é praticamente nula a atenção dada ao que ocorre do outro lado do Atlântico, num desinteresse sugestivo da desimportância de Portugal no âmbito das referências e interlocuções brasileiras.

Mas o fenômeno não se restringe ao nível médio das duas sociedades. Também no plano acadêmico, da chamada alta cultura, a assimetria manifesta-se. Veja-se, por exemplo, a preocupação de um Abel Barros Batista com a situação do ensino da literatura brasileira em Portugal. Sua percepção de que os alunos dos cursos de Letras entram na universidade sem terem o menor conhecimento a respeito da produção literária brasileira, se por um lado é um dado a sugerir que em Portugal o interesse pelo Brasil se restrinja à cultura de massa, por outro reforça a ideia de que haja um gasto de energia dos portugueses com o Brasil que absolutamente não encontra correspondência entre os brasileiros, já que se trata de um professor e crítico a tentar esmiuçar, em um livro de mais de 200 páginas $^{1}$, as razões para tal desconhecimento e, em seguida, propor uma estratégia visando a reversão do quadro.

Não há no cenário acadêmico brasileiro sinais de uma correspondência a essa atitude. O estudo universitário da literatura portuguesa é uma especialidade - literatura estrangeira entre outras - que, com variadíssimos graus de obrigatoriedade, aparece nos currículos mais em função daquele passado comum do que como índice de seu prestígio, uma condição tão marginal quanto a da literatura brasileira em Portugal, sem por isso provocar maiores comoções entre os professores e críticos nela especializados. Trata-se de uma situação que representa bem, no plano acadêmico, o desinteresse que se observa nos outros níveis da sociedade brasileira.

Os motivos para tal situação são muito complexos e nada consensuais, à partida porque envolvem pelo menos duas perspectivas distintas, a brasileira e a portuguesa. No limite, o tipo de relação que os dois países estabeleceram entre si é resultado não apenas da experiência histórica que lhe serve de lastro, prova material da trajetória comum, mas da imagem, ou imagens, que cada um construiu do outro e das maneiras como cada um 
se vê enquanto corpo coletivo. Como exemplo sintético, podemos evocar as palavras de Eduardo Lourenço, em uma de suas muitas voltas ao mote da atitude brasileira em relação a Portugal:

A autonegação ou denegação que a cultura brasileira faz de si mesma, ocultando, menosprezando ou, com mais verdade hoje, ignorando seu nódulo irredutível e indissolúvel português (que mais do que língua quer ser memória, cultura, rito e ritual), é tão absurda e delirante como a fixação possessiva, o amor imaginário que devotamos a um Brasil, não por ser o que ele é, e o merecer naquilo que é, mas por julgarmos que os brasileiros se vivem como continuação, ampliação ou metamorfose nossa.

Pura e desastrosa ilusão que está no centro do equívoco, nunca posto à mostra, como seria necessário para nos tornarmos mutuamente adultos nas nossas relações e acabar de vez com o esquema inadequado para elas, quer enquanto relação de colonizador-colonizado (...), quer enquanto ao esquema sentimental "pai", "filho" etc. ${ }^{2}$

O olhar de Lourenço vislumbra aquela diferença de perspectivas, nela identificando a dificuldade de comunicação entre as duas partes, que poderia não ter maiores consequências se não implicasse na manutenção de um estado de infantilismo prejudicial a ambas. Perspicaz em apontar os elementos responsáveis pelo ruído na comunicação, sua abordagem lida com dados pouco palpáveis, dificilmente mensuráveis por leituras que não tenham familiaridade com a fluidez e ambiguidade que caracterizam o que é da ordem do imaginário antes de se manifestar no plano histórico - o que, aliás, nem sempre acontece. Nesse sentido, a produção literária pode ser uma via de acesso a algumas linhas de força que sustentam tais imagens. Não foi à toa, então, que o próprio Eduardo Lourenço e Antonio Candido, dois intelectuais representativos do pensamento acerca das culturas brasileira e portuguesa, fizeram da literatura produzida em seus países de origem seu instrumento privilegiado de investigação. Em artigos hoje canônicos, como o são "Literatura e cultura de 1900 a 1945" e "Da literatura como interpretação de Portugal", Candido e Lourenço utilizam-se das mesmas balizas literárias - o romantismo e o modernismo - para identificar os momentos decisivos em que Brasil e Portugal encontraram-se consigo próprios. Observar o modo como cada um descreve tal trajetória, bem como o significado que lhe atribui, pode ajudar-nos a compreender as especificidades e os pontos de confluência de duas visadas críticas que têm por trás de si as complexas imagens que respondem pelos nomes de Brasil e Portugal. 
O ensaio de Candido, que tem o subtítulo de "Panorama para estrangeiros"- a registrar o espaço original de sua publicação, uma revista destinada a leitores de língua alemã, mas igualmente a indicar que seu conteúdo era do perfeito conhecimento dos brasileiros - inicia-se com a observação de que, se pudéssemos estabelecer uma "lei de evolução de nossa vida espiritual, poderíamos talvez dizer que toda ela se rege pela dialética do localismo e do cosmopolitismo" ${ }^{3}$, sendo que os melhores resultados da produção literária brasileira revelam o equilíbrio entre as duas tendências. Em seguida, "nossa rebeldia estereotipada contra o português", que teria caracterizado as relações culturais luso-brasileiras no século XIX, aparece como um "recurso de autodefinição", a recobrir "um fascínio e uma dependência”, superados no século XX, o que se provaria pela substituição daquela atitude rebelde por outras, as "mesuras acadêmicas, convênios ortográficos, exaltações e louvores recíprocos na retórica sentimental e vazia das missões culturais", indicativos de que a influência morreu, uma vez que a "vida se nutre de tensões e conflitos". ${ }^{4}$

Como se vê por este ponto de partida, o texto, publicado em duas partes em 1953 e 1955, já contém os elementos que nortearão as ideias do autor apresentadas longamente na Formação da literatura brasileira, com uma diferença que dá a medida da dificuldade do próprio crítico para chegar àquele equilíbrio. No artigo, o foco recai sobre a completa independência conquistada pela literatura brasileira do modernismo em relação à portuguesa:

O nosso modernismo importa essencialmente, em sua fase heroica, na libertação de uma série de recalques históricos, sociais, étnicos, que são trazidos triunfalmente à tona da consciência literária. Este sentimento de triunfo, que assinala o fim da posição de inferioridade no diálogo secular com Portugal e já nem o leva mais em conta, define a originalidade própria do Modernismo na dialética do geral e do particular. (...) As nossas deficiências, supostas ou reais, são reinterpretadas como superioridades. ${ }^{5}$

$\mathrm{Na}$ Formação, a conquista empreendida pelo movimento modernista parece não ter sido completa, se pensarmos nas palavras com que se apresenta a obra:

3 CANDIDO, Antonio. Literatura e cultura de 1900 a 1945. In: Literatura e sociedade. São Paulo: Companhia Editora Nacional, 1985. p. 109.

4 Idem, p. 111.

5 Idem, p. 119-120. 
A nossa literatura é galho secundário da portuguesa, por sua vez arbusto de segunda ordem no jardim das Musas... Os que se nutrem apenas delas são reconhecíveis à primeira vista, mesmo quando eruditos e inteligentes, pelo gosto provinciano e falta do senso de proporções. Estamos fadados, pois, a depender da experiências das outras letras (...). Comparada às grandes, nossa literatura é pobre e fraca. Mas é ela, não outra, que nos exprime. (...) Ninguém, além de nós, poderá dar vida a essas tentativas muitas vezes débeis, outras vezes fortes, sempre tocantes, em que os homens do passado, no fundo de uma terra inculta, em meio a uma aclimação penosa da cultura europeia, procuravam estilizar para nós, seus descendentes, os sentimentos que experimentavam, as observações que faziam, - dos quais se formaram os nossos. ${ }^{6}$

Aqui, a convicção estampada no artigo, em que se destacava a reinterpretação modernista de nossas "deficiências" como "superioridades", é substituída pela assunção de nossa "inferioridade", indicando-se dessa maneira que o triunfo modernista teve um alcance restrito. Nossas letras, e nossa cultura como um todo, talvez houvessem se libertado da influência daquele "arbusto de segunda ordem", o que, pelo menos de acordo com o que o movimento de Candido sugere, foi insuficiente para conferir-lhes a segurança para afirmar sua qualidade, livre do peso da comparação com as "grandes literaturas".

Se voltarmos às considerações de Lourenço há pouco citadas e as aproximarmos desta atitude conflituosa de Antonio Candido, veremos que, se houve o apagamento da nossa relação com Portugal a que se refere aquele crítico, ele esteve longe de ser um processo tranquilo, que nos levou a um estado de segurança e a uma imagem de autossuficiência. O problema da origem - o galho secundário no arbusto de segunda ordem - lá está, mais do que nunca provando ser "irredutível e indissolúvel" para os brasileiros o "nódulo português", ao menos não sem uma dose considerável de angústia e conflito. Reforçando a dificuldade envolvida em tal esforço de independência, a abordagem de Candido em seu artigo, sua caracterização do papel desempenhado pela literatura no processo de desenvolvimento da sociedade brasileira, tende a colocá-la numa situação análoga àquela em que a vemos posta por Eduardo Lourenço em "Da literatura". o crítico brasileiro dirá que, "diferentemente do que sucede em outros países, a literatura tem sido aqui, mais do que a filosofia e as ciências humanas, o fenômeno central da vida 
do espírito." A analogia encontra um ponto de divergência na compreensão de Candido de que, no Brasil, o lugar de destaque ocupado pela literatura resultou não de sua força intrínseca como modalidade discursiva privilegiada, mas de uma situação conjuntural:

A longa soberania da literatura tem, no Brasil, duas ordens de fatores. Uns, derivados de nossa civilização europeia e dos nossos contatos permanentes com a Europa, quais sejam o prestígio das humanidades clássicas e a demorada irradiação do espírito científico. Outros, propriamente locais, que prolongaram indefinidamente aquele prestígio e obstaram esta irradiação. (...) Ante a impossibilidade de formar aqui pesquisadores, técnicos, filósofos, ela preencheu a seu modo a lacuna, criando mitos e padrões para orientar e dar forma ao pensamento. ${ }^{8}$

De acordo com esta perspectiva, a literatura foi, então, um substituto para os discursos que promovem o conhecimento e a transformação, no plano científico e racional, da realidade, imagem que se vai consolidando à medida que a argumentação avança:

Justamente devido a essa inflação literária, a literatura contribuiu com eficácia maior do que se supõe para formar uma consciência nacional e pesquisar a vida e os problemas brasileiros. Pois ela foi menos um empecilho à formação do espírito científico e técnico (sem condições para desenvolver-se) do que um paliativo a sua fraqueza. Basta refletir sobre o papel importantíssimo do romance oitocentista como exploração e revelação do Brasil aos brasileiros. ${ }^{9}$

O interesse e a força do literário, nesse contexto carente de ciência e técnica, parecem residir justamente em sua possibilidade de servir como instrumento na "exploração e revelação do Brasil aos brasileiros", o que o teria levado a ocupar um lugar tão central nessa sociedade, a ponto de manter-se em destaque, mesmo diante do florescimento da pesquisa sociológica e política, ou, como diz o autor, "não obstante a ciência já haver, neste setor, alcançado e superado os recursos da ficção". ${ }^{10}$ Significativo da postura de Candido é o desdobramento que ele vislumbra em sua contemporaneidade: a partir do momento em que a literatura "volta-se sobre si mesma, especificando-se e assumindo uma configuração propriamente estética (...) deixa de ser

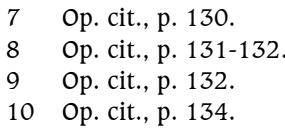


uma viga mestra, para alinhar-se em pé de igualdade com outras atividades do espírito". ${ }^{11} \mathrm{Na}$ sequência de uma argumentação que tanto valorizou o papel instrumental da literatura brasileira durante um período expressivo de sua história, não há como não supor que esta mudança de condição não implique em uma queda em sua importância social. Ao desconfiar de uma tendência literária cujas bases identifica no nacionalismo e na "pesquisa do Eu profundo" que, tendo bebido na mesma fonte do modernismo, com ele entraria em rota de colisão, configurando por isso uma reação às conquistas do movimento, Candido tende a desqualificar a produção que, naquele momento, para ele representaria o prolongamento problemático de ideais estéticos, ideológicos e políticos postos em cena pelo simbolismo. Também neste caso nota-se uma certa instrumentalização do literário, cujo interesse confunde-se com as tensões próprias do cenário político-ideológico em que se inscreve, o que redunda na marginalização de textos que não incorporem as questões nacionais a partir de certa orientação ideológica. Em tal perspectiva, o discurso literário que enfrenta o desafio de representar a subjetividade tenderá a ser desvalorizado por carecer de um empenho social, responsável por aquela grande contribuição que teria sido a do romance do século XIX, "a exploração e revelação do Brasil aos brasileiros".

Outra é a postura de Lourenço em "Da literatura como interpretação de Portugal"- como não poderia deixar de ser, considerando-se a especificidade do contexto e da experiência histórica e cultural que os dois críticos têm diante de si. Para ele, trata-se, antes de mais nada, de caracterizar a relação do escritor com a pátria, a partir do romantismo, como uma interpelação de dupla via. Como para Candido, trata-se, sem dúvida, de uma exploração de Portugal, mas sua revelação, essa carecerá da univocidade em que acredita o crítico brasileiro:

O que nos parece mais importante na atitude inaugural e, de algum modo, matricial, de Garrett, não é a sua descoberta das coisas portuguesas como dignas de interesse estético. Esse reflexo mimético pertence à essência mesma dos inovadores românticos, alemães e ingleses. O mais importante é o espetáculo da osmose profunda entre a sua particular aventura anímica e aquela de que Portugal - no passado e no presente - lhe parece centro. Garrett não pode saber quem é, nem o que verdadeiramente quer, sem interrogar a sério e de frente o que é essa realidade viva e mortal de uma Pátria entrevista como "frágil", "vulnerável" e da qual sente o seu ser interior e o seu destino pessoal inseparáveis. ${ }^{12}$

11 Op. cit., p. 131.

12 LOURENÇO, Eduardo. Da literatura como interpretação de Portugal. In: O labirinto da saudade. Lisboa: Dom Quixote, 1982. p. 83-84. 
No romantismo português encabeçado por Garrett, o elemento nacional não teria o caráter tópico que marcaria as matrizes alemã e inglesa do movimento - o que representaria em si um ponto importante na diferença de perspectivas entre este crítico e o brasileiro, considerando-se que em Portugal não se trataria meramente da importação do modelo estrangeiro, mas de uma apropriação submetida a um ajuste que a adequasse às exigências, muito particulares, do contexto de recepção. Não se justificaria, assim, a imagem do "arbusto de segunda ordem" criada por Candido, já que o arbusto em questão parece levar a marca de uma outra ordem.

O outro dado, mais relevante, diz respeito à relação que se estabelece entre autor e pátria. É de uma osmose que se trata, daí a ânsia com que Garrett se olhará no espelho que para ele é Portugal. E, para dar a medida da natureza de tal osmose, Lourenço caracteriza a pátria como mortal, um corpo vivo e, como tal, dificilmente abarcável por um único relance de olhos. De maneira que serão muitas as vezes que os sujeitos interpeladores, em busca de uma autoimagem definida - e, quem sabe, definitiva -, precisarão voltar seu olhar para o espelho, acompanhados da sensação de precariedade e parcialidade de sua empreitada. Quer isto dizer que nesse esforço de autognose, como o chama o crítico, as hipóteses de se chegar a contemplar a imagem límpida do outro lado do espelho têm muito de quiméricas. $O$ processo de interrogação é feito de uma sequência infinita - ou enquanto durar a vida da pátria e do interpelador - de perguntas cujas respostas corresponderão sempre a uma imagem pouco nítida, distante, do rosto que se almeja ver.

A trajetória literária que os escritores portugueses descreveram do romantismo ao modernismo levaria não ao ponto de chegada do processo de autognose, mas à compreensão do estado permanente de busca, o que se apresenta claramente já no início do texto:

Entre outras coisas, o Modernismo português - e em particular o representado por Fernando Pessoa - desejou ser não apenas invenção e recriação de uma nova sensibilidade e visão da realidade (aquela que o chamado mundo moderno estava pedindo), mas igualmente uma metamorfose total da imagem, ser e destino de Portugal. (...) O acesso e a conquista de uma nova visão de mundo, implica e procede de uma revisitação em profundidade do que Pessoa, na sequência de Pascoaes, chamará de alma nacional. o modernismo é para Fernando Pessoa uma questão que ele tem ao mesmo tempo com o mundo em que vive e com Portugal, mas por sua vez Portugal apresentou-se-lhe cedo como enigma objetivo com o qual há muito a consciência nacional se debate. ${ }^{13}$ 
O uso do termo enigma é suficiente para dar a dimensão da dificuldade para se chegar a uma resposta tranquilizadora, porque definitiva, no processo de autognose. Uma das preocupações de Lourenço é a de garantir, através desta caracterização orientada pelo enigma, que as imagens conflitantes ou problemáticas não sejam apagadas, sob pena de se mutilar aquele processo. Ao assumir a tarefa de decifração do enigma, construindo, através da criação heteronímica, um outro real que põe em xeque a própria convenção de realidade vigente, Pessoa a um só tempo inscreve-se no processo de autognose nacional - afinal, o jogo heteronímico baseia-se na definição sempre adiada, sempre frustrante do que seja a identidade - e na modernidade ocidental, marcada como é pela dificuldade em definirem-se os sujeitos que integram a sua igualmente difícil de definir realidade. O alcance da resposta de Pessoa ao enigma lançado pela pátria ultrapassa as fronteiras nacionais, tornando-o uma referência quando o assunto é a sensibilidade moderna:

O Modernismo de Pessoa não foi e não será nunca apologia e delírio da quotidianidade presente e suas fulgurações, mera apologia do novo, mas consciência das insolúveis contradições do mundo moderno e da mesma Modernidade, porventura até, rejeição do seu próprio espírito. De Portugal como realidade presente não espera Pessoa nada. Do Portugal como nauta de si mesmo (...), tudo. ${ }^{14}$

Se aceitarmos esta caracterização, poderemos dizer que a contribuição literária do poeta português corresponderia a um excelente exemplo daquele equilíbrio entre local e cosmopolita referido por Candido em seu artigo. $O$ curioso é que tudo isso se passou com alguém que não se furtou a dedicar-se, sistemática e profundamente, à "pesquisa do Eu profundo", que, de acordo com o crítico brasileiro, era um caminho problemático por desviar a atenção das questões nacionais. Antes de Pessoa, outro ponto alto na defesa de um olhar que não se intimide com eventuais julgamentos cujas balizas sejam externas ao contexto nacional é a leitura da contribuição de Teixeira de Pascoaes para a autognose coletiva através de sua "mítica e mística Saudade". Sem ter alcançado a mesma projeção internacional de seu contemporâneo, Pascoaes teria lançado as bases para o que depois foi o trabalho grandioso de Pessoa através de sua aguda compreensão da força transfiguradora e projetiva, não regressiva, da saudade: 
Mais importante que ter sido ou ter tido Império, mais decisivo que haver usufruído riquezas mortas, ou até ter sido atores de uma gesta científica que podíamos ter tido num grau e esplendor que não tivemos, é para Pascoaes o haver interiorizado como alma da nossa alma o sentimento obscuro mas iluminante dessa visão positiva da vida como sonho que se sabe sonho mas que no interior desse sentimento se recupera como criadora saudade, desejo de um Desejo que jamais tomará a forma de uma possessão idolátrica, subtraindo-nos assim, de raiz, à tentação moderna por excelência, a de Fausto: saber, poder para reinar sobre a Natureza e os Outros. ${ }^{15}$

Através de Pascoaes ter-se-ia uma reversão radical do sentido que se atribui à saudade como traço cultural português destituído de grandeza por representar um apego ao passado, cujo efeito seria o da apatia. A saudade não é descartada por não estar de acordo com o que se esperaria de um perfil moderno, como aconteceria se se decidisse pautar as imagens culturais nacionais por padrões definidos por um "lá fora" de onde emanaria uma verdade contra a qual não se poderia levantar sem correr-se o risco de cair no ridículo de ser-se caracterizado como país atrasado. De fato, na perspectiva de Lourenço, a saudade de Pascoaes é essencialmente moderna porque crítica em sua recusa a submeter-se a um domínio científico e racional da Natureza e dos Outros - domínio esse que parece ter seduzido Candido na altura em que escreveu seu artigo -, marca da modernidade auto-satisfeita, obsessivamente dedicada à perpetuação de seus valores, norteados por noções como a de avanço e de progresso.

Enquanto Lourenço adota uma postura que se esforça por ultrapassar os discursos da pequenez, da decadência e da falta de importância sem remédio, característicos de uma parcela considerável da intelectualidade portuguesa, Candido, como vimos, a propósito da condição brasileira, incorpora-os, dando a medida da dificuldade de se desvencilhar das imagens de inferioridade que predominam na autoimagem brasileira, como predominam na portuguesa. Ao descrever o contexto em que se organiza o processo de autognose nacional, Lourenço inclui todas as vertentes literárias, não se deixando conduzir por convicções de que a via dos realismos seja a mais adequada - a única, talvez - para levar a bom termo a empresa.

São dois modos de compreender o papel da literatura: interpelar/ interpretar, na perspectiva de Lourenço, revelar, na de Antonio Candido. Enquanto o primeiro opta por assumir a ausência de uma resposta direta, objetiva, para o processo, o segundo agarra-se à ideia contrária, mesmo 
correndo o risco de contradizer-se. Isto nos leva de volta ao trecho do artigo de Eduardo Lourenço com que abri estas considerações. Diante da angústia que sobressai na abordagem de Candido, talvez não seja possível falar em "autonegação ou denegação" como características da cultura brasileira; o que nos assombra talvez seja justamente o oposto disso, e nos lançamos à autognose com tanta urgência que para nós torna-se insuportável aceitar a ideia de que não nos seja dada uma revelação objetiva de nós próprios, insuportável vislumbrar que de objetivo só haja mesmo o enigma.

\section{REFERÊNCIAS}

CANDIDO, Antonio. Literatura e cultura de 1900 a 1945. In: Literatura e sociedade. São Paulo: Companhia Editora Nacional, 1985.

Itatiaia, 1981. Vol. 1.

. Formação da literatura brasileira. Momentos decisivos. Belo Horizonte: Editora

LOURENÇO, Eduardo. Da literatura como interpretação de Portugal. In: O labirinto da saudade. Lisboa: Dom Quixote, 1982.

Nós e o Brasil: ressentimento e delírio. In: A nau de Ícaro. São Paulo: Companhia das Letras, 2001.

Submetido em: 11/08/2014

Aceito em: 17/10/2014 